\title{
Occupational asthma in New Zealanders: a population based study
}

D Fishwick, N Pearce, W D'Souza, S Lewis, I Town, R Armstrong, M Kogevinas, J Crane

\begin{abstract}
Objectives-To examine the effect of occupation on respiratory symptoms in a randomly selected adult population aged 20-44 years.

Methods-It is based on the phase II sampling of the New Zealand part of the European Community respiratory health survey. 1609 people (63.9\% response rate) completed a detailed respiratory questionnaire. Of those responding, 1174 (73\%) underwent skin tests and 1126 (70\%) attended to undergo methacholine bronchial challenge. Current occupation was recorded and a previous occupation was also recorded if it had led to respiratory problems. 21 occupational groups were used for analysis for the five definitions of asthma: wheezing in the previous 12 months; symptoms related to asthma; bronchial hyperresponsiveness (BHR); BHR with wheezing in the previous 12 months; and BHR with symptoms related to asthma.
\end{abstract}

Results-Prevalence odds ratios (ORs) were significantly increased for farmers and farm workers (OR $4 \cdot 16,95 \%$ confidence interval (95\% CI) 1.33 to $13 \cdot 1$ for the combination of wheezing and BHR). Increased risks of prevalence of asthma were also found for laboratory technicians, food processors (other than bakers), chemical workers, and plastic and rubber workers. Workers had also been divided into high and low risk exposure categories according to relevant publications. The prevalence of wheezing was greater in the high risk group (OR 1.57, $95 \% \mathrm{CI} 0.83$ to 2.95 ) than in the low risk group. Atopy was associated with asthma, but the prevalence of atopy did not differ significantly between occupational exposure groups. The attributable risk of wheezing that occurred after the age of 15 years and that was estimated to be due to occupational exposure (based on the defined high risk group) was $1.9 \%$, but this increased to $3 \cdot 1 \%$ when farmers and food processors (other than bakers) were also included in the high risk group.

Conclusions-This population based study has identified certain occupations significantly associated with combinations of asthmatic symptoms and BHR.

(Occup Environ Med 1997;54:301-306)
Keywords: asthma; occupations; bronchial hyperresponsiveness

The SWORD project in the United Kingdom has identified occupational asthma as the most common occupationally related diagnosis since its reporting system started. ${ }^{1}$ It is well known that occupational exposures can also be major causes of asthma and other respiratory conditions. Recognised occupational causes of asthma include laboratory animals, enzymes, flour dust, isocyanates, colophony flour, and oil mists ${ }^{2}$ among others. ${ }^{3}$ However, there has been little research to date on occupational respiratory disease in New Zealand, where the pattern of occupational exposures may differ from other industrialised countries, because of the importance of agricultural and related industries. There have been no previous population based studies to assess the relative contribution of various occupations on prevalence of asthma in New Zealand. Estimates of the proportion of adult asthma due to occupation vary greatly in other countries $^{4-11}$ ranging from $2 \%$ to $30 \%$, although most estimates are in single figures. Previous population based studies ${ }^{12} 16$ have tended to concentrate on the effects of occupational exposures on lung function and respiratory symptoms. Data from disease registers ${ }^{6}$ may result in an underestimation of the true prevalence of occupational asthma, and population based studies are required.

This study examines the self reported occupational history of workers in a sample of 1609 New Zealanders aged $20-44$ years and relates the prevalence of reported respiratory symptoms and measured bronchial hyperresponsiveness (BHR) to current occupation.

\section{Methods}

SUBJECTS

The study was based on the phase II sampling in the New Zealand part ${ }^{17}$ of the European Community respiratory health survey. ${ }^{18}$ Briefly, a random sample $(n=14318)$ of the population aged 20-44 years living in four areas of New Zealand were contacted and asked to complete a short screening questionnaire on respiratory symptoms. Of these, $11978(83.7 \%)$ responded to this initial phase.

In the second phase of the study we contacted 2004 (a $22 \%$ random subsample) subjects from three of the four original areas, and 
an additional subsample of 515 people (from the same three areas) who reported respiratory symptoms in the screening questionnaire but who had not been already selected in the random sample. Study participants were asked to complete a detailed questionnaire (including questions on occupational history), to undergo skin tests, and to perform spirometry as well as a methacholine challenge.

Altogether 1609 (63.9\%) subjects completed the more detailed questionnaire from the 2519 invited to do so. Of these, 1128 $(70 \cdot 1 \%)$ attended to undergo a methacholine challenge test and $1174(73 \%)$ underwent skin testing.

The questionnaire included a comprehensive enquiry on respiratory symptoms, smoking, and occupation. Previous occupations were also recorded if the workers had changed employment at any time in the past due directly to respiratory symptoms.

DEFINITIONS OF ASTHMA AND BRONCHIAL REACTIVITY USED

The definitions of asthma and BHR used in this analysis were those used for a similar analysis of occupation and asthmatic symptoms based on a young adult Spanish population. ${ }^{19}$ Five separate definitions were used:

(1) Wheezing or whistling: a report of wheezing or whistling in the chest during the past 12 months (subsequently referred to as wheezing).

(2) Asthmatic symptoms or medication: a report of an attack of asthma during the past 12 months, or of having been woken by an attack of shortness of breath during the past 12 months, or of taking asthma medication currently.

(3) BHR alone: a separate analysis was performed with BHR data alone, regardless of the presence or absence of respiratory symptoms. This was defined as a $20 \%$ fall in forced expiratory volume in one second $\left(\mathrm{FEV}_{1}\right)$ from the highest $\mathrm{FEV}_{1}$ (after diluent inhalation) during methacholine challenge. Basal $\mathrm{FEV}_{1}$ was recorded as the best of five forced expiratory manoeuvres and similarly the best of two values of $\mathrm{FEV}_{1}$ was taken after each incremental dose of methacholine. A total cumulative dose of 1 or $2 \mathrm{mg}$ of methacholine was used, unless the person developed a fall in $\mathrm{FEV}_{1}$ of $20 \%$ or more. The analysis of those asthma definitions incorporating BHR has been confined strictly to people either with or without a $20 \%$ fall in $\mathrm{FEV}_{1}$ during methacholine challenge for the purpose of this study. Some people $(n=56)$ were excluded from the challenge protocol because of low basal lung function (with a more than $15 \%$ bronchodilator response) and others $(n=22)$ were excluded from further continuing into a methacholine challenge if they developed more than a $10 \%$ fall in FEV after the control dose of diluent. It is arguable that these represent an additional group with BHR, but the numbers were small and their inclusion or exclusion made little difference to the results. This extra group with BHR has been excluded from all main analyses although further comments about these people are made.
(4) BHR and wheezing: the combinations of definitions 1 and 3 above.

(5) BHR and symptoms related to asthma: the combination of definitions 2 and 3 above.

\section{ATOPY}

Atopy was defined as having a positive skin prick test (a weal diameter greater or equal to 3 $\mathrm{mm}$ ) to one or more of: Dermatophagoides pteronyssinus; timothy grass; and cat. Skin tests were performed on the forearm with a positive control of histamine and a negative control of saline.

\section{OCCUPATIONAL HISTORY}

Occupation was coded according to the response to the question; "what is or was your current or most recent job?" Also, if people reported a change of job related to breathing problems, the job at that time was also noted and was used in the analysis rather than the most recent job. Each of these occupations was initially coded into one of the 350 Office of Populations, Censuses and Surveys (OPCS) (1980) codes. $^{20}$ Subsequently, these were converted into one of 21 combined groups as used in the SWORD project to classify occupations, ${ }^{6}$ and these 21 groups formed the basis of the data analysis. With the approach used by Kogevinas et al, ${ }^{19}$ a group of high risk occupations was defined, on the basis of previous reports. ${ }^{21}$ This comprised the following categories: laboratory workers (occupational code 6), bakers (code 9), rubber and plastics workers (code 10), chemical industry processing workers (code 11), electrical, welding, and soldering (code 13), metal making and treatment (code 14), and sprayer painters (code 17). All other occupations were considered to be at low risk.

\section{DATA ANALYSIS}

The data were analysed as prevalence odds ratios $(\mathrm{ORs})^{45}$ for various combinations of asthmatic symptoms or BHR. In each analysis, cases were derived from both subsamples (the $22 \%$ random subsample, and the enriched subsample which included all subjects who reported symptoms related to asthma in the screening questionnaire but who were not selected in the random subsample), whereas controls were derived exclusively from the $22 \%$ random subsample. This exclusion was made because the additional subsample was entirely made up of people who had reported asthmatic symptoms in the original survey, and it was considered inappropriate for them to be included in a disease free control group. When the analysis was based entirely on the random subsample alone (excluding both cases and controls from the enriched subsample), there was little change in the study findings. The cases (but not the controls) from the enriched subsample are therefore included in all analyses in this paper.

For each definition of asthma, prevalence ORs were calculated for each of the 21 occupational groups. All ORs calculated with SAS $^{43}$ were adjusted (table 1) for age, sex, and tobacco smoking with the Mantel-Haenszel 
Table 1 Characteristics of the study population

\begin{tabular}{lc}
\hline & $n(\%)$ \\
\hline Area of residence: & \\
Hawkes Bay & $402(25 \cdot 0)$ \\
Christchurch & $619(38 \cdot 5)$ \\
Wellington & $588(36 \cdot 5)$ \\
Total & $1609(100)$ \\
Sex: & $739(45 \cdot 9)$ \\
Men & $870(54 \cdot 1)$ \\
Women & $444(27 \cdot 6)$ \\
Age (y): & $698(43 \cdot 4)$ \\
$20-29$ & $467(29 \cdot 0)$ \\
$30-39$ & $783(48 \cdot 7)$ \\
$40-44$ & $485(30 \cdot 1)$ \\
Smoking: & $341(21 \cdot 2)$ \\
Non-smokers & $681(58)$ \\
Ex-smoker & $493(42)$ \\
Current smoker & 435 \\
Atopy: & \\
Non-atopic & $542(48)$ \\
Atopic & $376(33)$ \\
Not tested & \\
Methacholine reactivity: & $22(2)$ \\
No BHR & $56(5)$ \\
BHR & \\
Bronchoconstricted to control & \\
diluent during challenge & $132(12)$ \\
Excluded due to low basal lung function & \\
Unsatisfactory, asked to stop or basal & \\
lung function only measured & \\
Not tested & \\
\hline
\end{tabular}

method. ${ }^{44}$ Smoking was defined as either a current smoker, an ex-smoker, or a never smoker. The control group was the "remaining professional, clerical, and administrative workers".

To assess the proportion of prevalence of asthma within the population that could be attributed to occupational exposure, the population attributable risk ${ }^{22}$ was estimated for the high risk occupations and for the low risk occupations with each of the definitions of asthma that incorporated symptoms in their definition. All attributable risks were estimated after adjustment for age, sex, and smoking habit. Also, an analysis was performed excluding workers whose symptoms began before the age of 15 years to exclude workers with asthma that started during childhood.

\section{Results}

Table 1 shows the study population according

Table 2 Prevalence ORs for asthmatic symptoms by occupational group

\begin{tabular}{|c|c|c|c|}
\hline \multirow[b]{2}{*}{ Occupational code } & \multirow[b]{2}{*}{$n$} & \multicolumn{2}{|c|}{ Wheezing } \\
\hline & & $n$ & $O R^{*}(95 \% C I)$ \\
\hline \multicolumn{4}{|l|}{1 Remainder professional, administrative, } \\
\hline 2 Cleaners & 26 & 12 & $0.90(0.40$ to 2.02$)$ \\
\hline 3 Nurses & 54 & 23 & $1.05(0.60$ to 1.83$)$ \\
\hline 4 Farmers, farm workers & 13 & 10 & $4 \cdot 27(1.28$ to $14 \cdot 29)$ \\
\hline 5 Hairdressers & 11 & 2 & $0.28(0.06$ to 1.27$)$ \\
\hline 6 Laboratory technicians, assistants & 9 & 4 & $1.23(0.33$ to 4.56$)$ \\
\hline 7 Woodworkers & 14 & 8 & $1.94(0.67$ to 5.63$)$ \\
\hline 8 Other food processors & 24 & 16 & $2.45(1.05$ to 5.72$)$ \\
\hline 9 Bakers & 4 & 1 & $0.33(0.03$ to 3.77$)$ \\
\hline 10 Plastics, rubber workers & 7 & 4 & $2.08(0.48$ to 9.04$)$ \\
\hline 11 Chemical processors & 3 & 3 & $4.61(0.71$ to 30.02$)$ \\
\hline \multicolumn{4}{|l|}{$\begin{array}{l}12 \text { Remainder non-metal or } \\
\text { non-electrical processors }\end{array}$} \\
\hline \multicolumn{4}{|l|}{$\begin{array}{l}\text { non-electrical processors } \\
13 \text { Welders, solderers, and electronic }\end{array}$} \\
\hline processors & 10 & 5 & $1 \cdot 19(0.29$ to $4 \cdot 86)$ \\
\hline 14 Metal making and treating & 0 & - & \\
\hline 15 Remainder metal and electrical & 78 & 27 & $0.78(0.47$ to 1.29$)$ \\
\hline 16 Other painters & 8 & 4 & $1.04(0.22$ to 4.90$)$ \\
\hline 17 Spray painters & 6 & 3 & $1.10(0.25$ to 4.77$)$ \\
\hline \multicolumn{4}{|l|}{18 Remainder painting, assembly, } \\
\hline and packaging & 7 & 3 & $0.88(0.26$ to 2.98$)$ \\
\hline 19 Construction, mining & 18 & 8 & $1.07(0.39$ to 2.94$)$ \\
\hline 20 Transport and storage & 40 & 13 & $0.61(0.30$ to 1.23$)$ \\
\hline 21 Housewives or inadequately described & 60 & 30 & $1.50(0.88$ to 2.55$)$ \\
\hline
\end{tabular}

*Adjusted for age, sex, and tobacco smoking. to standard demographic data, smoking status, and outcome of testing for atopy and BHR. Altogether 56 people were excluded from the BHR tests due to low basal lung function and 27 of these underwent bronchodilator challenge. Ten of these improved their $\mathrm{FEV}_{1}$ by at least $15 \%$. Similarly, 22 people reduced their $\mathrm{FEV}_{1}$ by at least $10 \%$ after the initial control dose of diluent during the methacholine challenge.

OCCUPATIONAL EXPOSURES

Tables 2 and 3 present the ORs and their associated $95 \%$ confidence intervals (95\% CIs) for the prevalence of wheeze (table 2) or BHR (table 3) within each occupational group in comparison with the control group. There was much variation in the effect of occupation on the reported levels of asthmatic symptoms and BHR. Within this wide range, however, the findings within certain occupational groups were consistent.

Farmers and farm workers showed a significant increase in asthma as measured by the presence of wheezing alone (OR 4.27) and wheezing with BHR (OR 4.16).

Laboratory technicians showed associations with definitions of asthma incorporating the measurement of BHR and a significant association was noted for BHR (regardless of respiratory symptoms) with an OR of 4.94 . This occupation did not seem to be associated with asthma defined purely on symptoms although the numbers involved were small and the $95 \%$ CIs were wide.

Food processors (other than bakers) showed consistent significant associations with asthma defined from the questionnaire alone (OR for wheezing 2.45). However, there was little or no evidence of an excess risk for this group when BHR measurements were included in the definition of asthma.

Although there were few chemical processors in this study (and therefore all of the $95 \%$ CIs included 1.0), associations with all definitions of asthma were found. Also, plastic and rubber work was associated with increased wheezing and BHR.

None of the ORs calculated for the presence of asthmatic symptoms were significant, although there seemed to be an association between asthmatic symptoms and farmers (OR $1 \cdot 95,95 \%$ CI 0.74 to $5 \cdot 11$ ), other food processors (OR 2.14, 95\% CI 0.94-4.86) and chemical processors (OR $3 \cdot 12,95 \%$ CI 0.43 to $22 \cdot 72$ ). Similarly, when asthma was defined as the combination of asthmatic symptoms and BHR, this was associated with farmers.

All prevalence ORs in table 3 were also recalculated incorporating the extra people with BHR into the analysis (not shown in the table). There was little change in the overall results and no changes in significance (in either direction) between definitions of asthma and occupational groups.

\section{ATTRIBUTABLE RISK}

The 21 occupational groups were also grouped into high risk and low risk occupations as already described. However, the high risk group 
Table 3 Prevalence ORs for BHR and asthmatic symptoms by occupational group

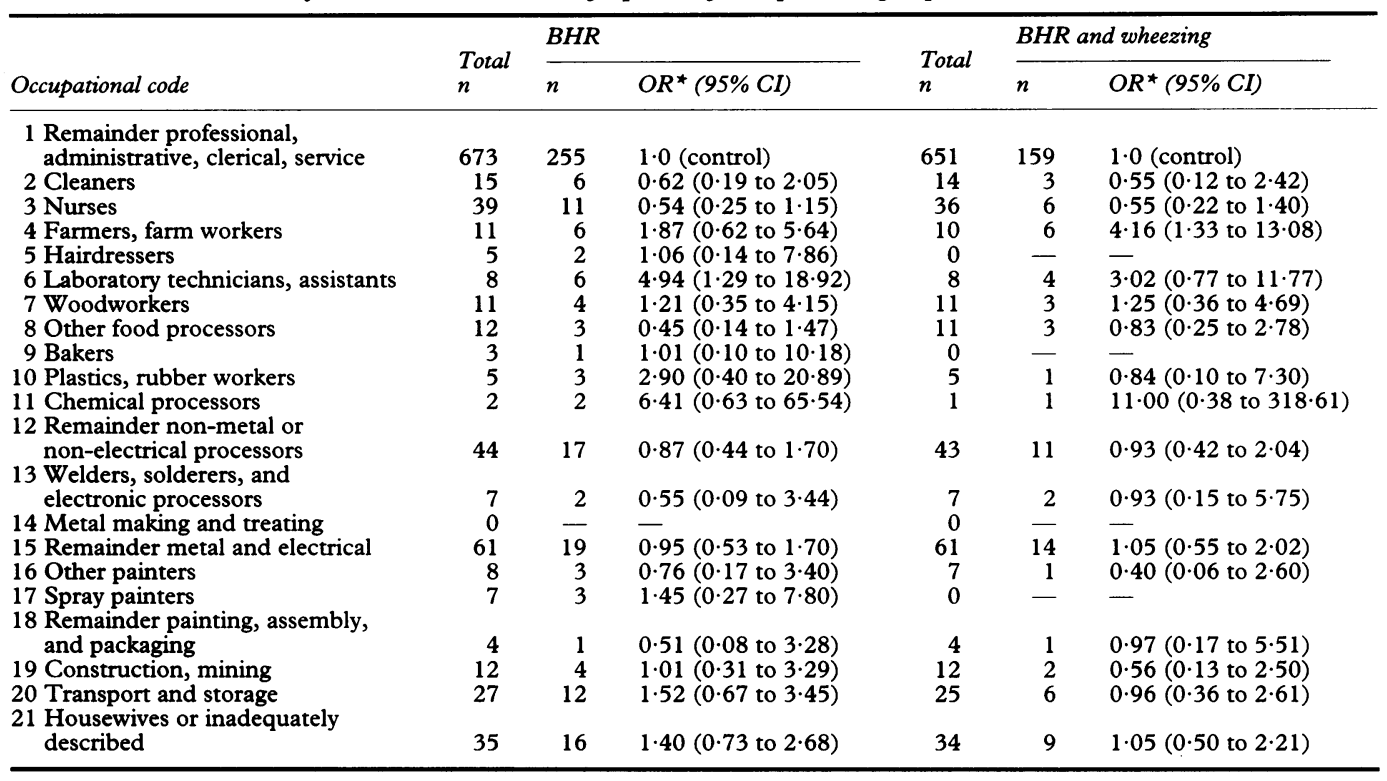

${ }^{\star}$ Adjusted for age, sex, and tobacco smoking.

contained only 39 workers, and the population attributable risks were low in general, the highest being $1.9 \%$ for wheezing beginning after the age of 15 years. To assess the potential contribution of the two occupational groups with particularly high levels of wheezing identified in this study (farmers and food processors), the analysis of attributable risk was performed again including these two groups into the high risk group. This showed an attributable risk of $3 \cdot 1 \%$.

\section{SELECTION BIAS}

We examined separately the effect of using current occupation alone as described by a worker or taking into account occupation at the time of worsening respiratory symptoms (used throughout the analysis). The results of this analysis suggest that in this population, no differences were found when changing the occupation used in the analysis. For example, when the code of the current occupation was used, the level of wheeze was slightly higher in the high risk group (adjusted OR 1.36, 95\% CI 0.73 to 2.53 ) than in the low risk group. The corresponding $\mathrm{OR}$ calculated when the occupation at the time of respiratory problem was used was $1 \cdot 42(95 \%$ CI 0.76 to $2 \cdot 67)$.

\section{ATOPY}

Atopy was predictably associated with the combination of wheezing and BHR; (OR 5.94, 95\% CI 4.35 to $8 \cdot 16$ ). When workers were separated according to low and high risk of exposure, and the non-exposed and non-atopic workers were taken as the control group, asthma was greater both in the low risk atopic group (OR 5.86) and in the high risk atopic group. ${ }^{613}$ When only atopic workers were considered, differences in the prevalence of asthma between high and low occupational exposure groups was not significant (OR 1.04 for the high risk group). When non-atopic people were considered, the prevalence of asthma tended to be lower in the high risk group (OR 0.61) than in the low risk group.

\section{Discussion}

We have identified certain occupations that are related to symptoms of asthma and measurements of BHR in this population study based on adults in New Zealand. The findings were generally dependent on the definition of asthma used as the numbers diagnosed with asthma fell from 633 with wheezing to 176 with asthmatic symptoms and BHR combined. However, the results in general tended to be consistent within an occupational category.

The highest risk occupations were found to be farmers and farm workers, laboratory technicians and assistants, food processors other than bakers, plastics and rubber workers, and chemical processors.

Farmers are exposed to many agents at work that are known to cause occupational asthma. New Zealand farming has a fairly diverse mix of dairy, poultry, sheep, meat produce, and agricultural components allowing a huge potential mix of exposures within this group. Animal products, ${ }^{2324}$ components of grain ${ }^{25} 26$ and mites $^{27}$ have all been implicated in asthma as well as possible chemical exposures. ${ }^{28}$

The finding that laboratory technicians and assistants had an increased prevalence of asthma concords with the well documented risk of occupational asthma in this group. ${ }^{629-31}$ It is interesting to note that within this group two workers had asymptomatic BHR. The significance of this finding, however, is difficult to interpret in this study.

A rather surprising finding relates to the association between food processors (other than bakers) and asthma as defined by questionnaire responses alone (wheezing and ARS). The association was striking for both definitions of asthmatic symptoms. Asthma in the food processing industry is well described but is usually based on people or types of specific processes-for example, coffee bean processing, ${ }^{32}$ and leaf tea ${ }^{33}$ and herbal tea ${ }^{34}$ manufacture. Various types of seafood processing are also associated with occupational asthma ${ }^{35-37}$ and this group may 
have relevance for New Zealand, with many workers employed in differing occupations with exposure to seafood. On further more detailed analysis of the occupations recorded by these workers, most described work as either general food and deep freeze workers, or meat workers and processors. These job types were similar between cases of wheeze and controls within this occupational group.

Chemical processors (including pharmaceutical workers) showed universally increased ORs to all definitions of asthma although the numbers were so small that interpretation of the findings are difficult. However, it is certainly possible that these workers were exposed to chemicals or pharmaceutical agents known to cause asthma. ${ }^{21}$

On the other hand, this study did not find increased risks for some occupational groups that have been identified in previous studies, and the overall high risk group showed lower ORs than in a similar analysis in Spain.

The predefined high risk group in this population only contained 39 workers and the groupings used did not generally contain those workers with the highest levels of asthma. The calculated attributable risks, therefore, were all found to be low with the maximum being for asthmatic symptoms starting after 15 years of age with wheezing as the definition. This model calculated an attributable risk of $1.8 \%$ whereas Kogevinas et al ${ }^{19}$ estimated the proportion of asthma accounted for by occupation in a group of Spanish adults identified in the European respiratory health survey to be between $2 \cdot 6 \%$ and $6.7 \%$ depending on the definition used. The lower findings in this study may reflect either a true low attribution of asthma to the occupational exposure or more likely that the numbers in this group were low and may not have fully described local New Zealand high risk occupations. In particular, the high risk group did not include farmers and other food processors which are common occupations and showed relatively high risks in New Zealand and the inclusion of these groups would have increased the attributable risk to $3 \cdot 1 \%$.

Some groups - for example, bakers and spray painters-known to be associated with occupational asthma, ${ }^{38}{ }^{39}$ did not show any excess risks in this study. This may reflect the size of each particular group or may truly reflect a low prevalence of respiratory problems due to differing work materials and practice in this country.

Similarly, no effect was found for the group of woodworkers despite the known association between exposure to wood dust and asthma. ${ }^{40} 45$ This may be due to the types of occupations found within this group, particularly relating to method of exposure to wood dust as - for example, either a carpenter or forestry worker-and also to the variations in wood type used in New Zealand. The proportion of woodworkers exposed to western red cedar and other woods known to increase the risk of asthma is likely to be much lower than in parts of the Pacific North West of the United States and Canada. However, one previous New Zealand study ${ }^{45}$ has documented occupational asthma in woodworkers.
Hairdressers had strikingly low levels of prevalence of asthma particularly in view of the potential for exposure to agents known to cause occupational asthma in this environment. ${ }^{41}$

The response rate in this study of $63.7 \%$ of those invited to take part in the second phase may bias the interpretation of the results. The direction of this potential bias is not known but it is important to note that the study was primarily designed to investigate exposures other than occupation. It is therefore less likely that people would choose to participate or otherwise on the basis of their current occupation, although it is possible that certain workers in manual jobs would find it less easy to find time to participate in the study.

Certain people agreed to take part in the second phase but declined bronchial challenge tests. A smaller proportion refused skin tests. There were no differences in age distribution between those who underwent challenge tests and skin tests and those who refused. A consistent finding, however, was that more men than women and more never smokers and less exsmokers underwent these investigations by comparison with those who declined. Current smoking was itself associated with two definitions of asthma - both those involving wheezing-whereas an association with definitions including asthmatic symptoms was not found. This may imply that wheezing is a symptom more likely to occur in other patients with nonasthmatic diagnoses related to smoking, such as chronic obstructive pulmonary disease or chronic bronchitis.

The potential role of smoking, however, remains important as exposure to tobacco smoke is known to influence the development of occupational asthma in certain instances. ${ }^{11} 42$ However, the ORs for effect of occupation when adjusted for age, sex, and smoking in general altered the outcome only slightly, suggesting that most of the measured effect related primarily to differences in occupation.

The effect of atopic status on the presence of asthma was examined by comparing prevalence of asthma across high and low risk exposure groups. Although asthma was greater in atopic workers, there was no effect of exposure group on the presence of asthma.

In conclusion, this population based study of adults in New Zealand has identified certain occupations that are clearly associated with the presence of asthma diagnosed either on the basis of questionnaire responses alone or in conjunction with BHR measurements. Occupational asthma is now the most common form of occupational lung disease in many countries of the world. Identified cases of occupational asthma almost certainly represent a small proportion of all cases and this remains a potential problem for all workers exposed and potentially exposed to known causative agents. The Wellington Asthma Research Group is funded by a pro-
gramme grant and JC and NP are funded by professorial gramme grant and JC and NP are funded by professorial research fellowships from the Health Research Council of New Zealand. The Christchurch work was supported by the Canterbury Medical Research Foundation and the Canterbury
Asthma Society. The work of DF was supported in part from 
the Northern Regional Health Authority of the United Kingdom. The work of Lisa Bradshaw, senior research nurse, is also acknowledged for help with analysis and preparation of this paper.

1 Meredith SK, Taylor VM, McDonald JC. Occupational respiratory disease in the United Kingdom 1989: a report to the British Thoracic Society by the SWORD project group. Br F Ind Med 1991;48:292-8.

2 Newman Taylor A. Asthma. In: MacDonald JC, ed. Epidemiology of work-related diseases. London: BMJ Epidemiology of work-rela

3 Burge PS. Occupational asthma. In: Brewis RAL, Gibson GJ, Geddes DM, eds. Respiratory medicine. London: Baillière Tindall, 1990:704-21.

4 Keskinen H, Alanko H, Saarinen L. Occupational asthm in Finland. Clin Allergy 1978;8:569-79.

5 Brooks SM. Bronchial asthma of occupational origin Scand 7 Work Environ Health 1977;53-72.

6 Meredith S. Reported incidence of occupational asthma in the United Kingdom. I Epidemiol Community Health 1993;47:459-63.

7 Gannon PFG, Sherwood Burge P, on behalf of the Midlands Thoracic Society Research Group. The SHIELD scheme in the West Midlands Region, United Kingdom. Br f Ind Med 1993;50:791-6.

8 Ng TP, Hong CY, Goh LG, Wong ML, Chung Koh KT, Ling SL. Risks of asthma associated with occupations in community-based case-control study. $\mathrm{Am} \mathcal{F}$ Ind Med 1994;25:709-18

9 Xu Xiping, Christiani DC. Occupational exposures and physician-diagnosed asthma. Chest 1993;104:1364-70

10 Blanc P. Occupational asthma in a national disability survey. Chest 1987;92:613-7.

11 Chan-Yeung $M$. Assessment of asthma in the workplace. Chest 1995;108:1084-117.

12 Krzyzanowski M, Kauffmann F. The relation of respiratory symptoms and ventilatory function to moderate occupational exposure in a general population. Int $f$ Epidemiol 1988;17:397-406.

13 Viegi G, Prediletto R, Paoletti P, Carrozzi L, di Pede F, Vellutini $M$, et al. Respiratory effects of occupational exposure in a general population sample in North Italy. Am Rev Respir Dis 1991;143:510-6.

14 Korn RJ, Dockery DW, Speizer FE, Ware JH, Ferris Jr. BG. Occupational exposures and chronic respiratory symptoms. Am Rev Respir Dis 1987;136:298-304

15 Bakke PS, Baste V, Hanoa R, Gulsvik A. Prevalence of obstructive lung disease in a general population: relation to occupational title and exposure to some airborne agents. Thorax 1991;46:863-70.

16 Heederick D, Kromhout H, Kromhout D, Burema J, Biersteker K. Relations between occupation, smoking, lung function, and incidence and mortality of chronic non-specific lung disease: the Zutphen study. $B r \mathcal{F}$ Ind non-specific lung disea

17 Crane J, Lewis S, Slater T, Crossland L, Robson B, D'Souza W, et al. The self reported prevalence of asthma symptoms amongst adult New Zealanders. NZ Med $\mathcal{F}$ 1994;107:417-2

18 Burney PGJ, Luczynska C, Chinn S, Jarvis D. The European Community Respiratory Health Survey. Eur Resp F 1994;7:954-60.

19 Kogevinas M, Anto JM, Soriano JB, Tobias A, Burney P, and the Spanish Group of the European Asthma Study. The risk of asthma attributable to occupational exposures. A population based study in Spain. Am $\mathcal{F}$ Respir Crit Care Med 1996;154:137-43.

20 Office of Population Censuses and Surveys. Classification of occupations 1980. HMSO. London.

21 Chan-Yeung M, Malo J-L. Aetiological agents in occupa- tional asthma. Eur Respir F 1994;7:346-7

22 Last JM. A dictionary of epidemiology. New York: Oxford University Press, 1988

23 Mantyjarvi J, Ylonen R, Taivainen A, Virtanen T, et al. IgG and IgE antibody responses to cow dander in farmers with cow induced asthma. Clin Exp Allergy 1992;22:83-90.

24 Bar-Sela S, Teichtahl H, Lutsky I. Occupational asthma in poultry workers. F Allergy Clin Immunol 1984;73:271-5.

25 Cuthbert OD, Jeffrey IG, McNeill HB, Wood J, Topping MD. Barn allergy amongst Scottish farmers. Clin Allergy' 1984:14:197-206.

26 Blainey AD, Topping MD, Ollier S, Davies RJ. Allergic respiratory disease in grain workers: the role of storage mites. F Allergy Clin Immunol 1989;84:296-303.

27 Cuthbert OD, Brostoff J, Wraith DG, Brighton WD. "Barn allergy": asthma and rhinitis due to storage mites. Clin Allergy 1979;9:229-36.

28 Honda I, Kohrogi H, Ando M, et al. Occupational asthma induced by the fungicide tetrachloroisophthalonitrile. Thorax 1992;47:760-1.

29 Newman Taylor AJ, Gordon S. Laboratory animal and insect allergy. In: Bernstein IL, Chan Yeung M, Malo JL, Bernstein DI, eds. Asthma in the workplace. New York: Marcel Dekker, 1993:399-414.

30 Venables KM, Tee RD, Hawkins ER, Gordon DJ, Wale CJ, Farrer NM, et al. Laboratory animal allergy in a pharCJ, Farrer NM, et al. Laboratory animal allergy in a

31 Burge PS, Edge G, O'Brien IM, Harries MJ, Hawkins R, Pepys J. Occupational asthma in a research centre breeding locusts. Clin Allergy 1980;10:355-63.

32 Jones RN, Hughes JM, Lehrer SB, Butcher BT, Glindmeyer HW, Diem JE, et al. Lung function consequences of exposure and hypersensitivity in workers who process green coffee beans. Am Rev Respir Dis 1982, 125:199-202.

33 Cartier A, Malo JL. Occupational asthma due to tea dust. Thorax 1990;45:203-6.

34 Blanc PD, Trainor WD, Lim DT. Herbal tea asthma. $\mathrm{Br} F$ Ind Med 1986;43:137-8.

35 Cartier A, Malo JL, Forest F, Lafrance M, Pineau L, St Aubin JJ, et al. Occupational asthma in snow crab proAubin Jj, et al. Occupational asthma in snow crab pro-

36 Tomaszunas S, Weclawik Z, Lewinski $M$. Allergic reaction to cuttlefish in deep sea fishermen. Lancet 1988; $1116-7$.

37 Sherson D, Hansen I, Sigsgaard T. Occupationally related respiratory symptoms in trout processing workers. Allerg 1989;44:336-41

38 Block G, Tse KS, Kijek K, Chan H, Chan-Yeung M. Bakers asthma. Clin Allergy 1983;13:359-70.

39 Vandenplas O, Malo JL, Saetta M, Mapp CE, Fabbri LM. Occupational asthma and extrinsic allergic alveolitis due to isocyanates: current status and perspectives. $\mathrm{Br} F$ Ind Med 1993;50:213-28.

40 Chan-Yeung $M$. Western red cedar and other wood dusts. In: Bernstein IL, Chan Yeung M, Malo JL, Bernstein DI, In: Bernstein IL, Chan Yeung M, Malo JL, Bernstein DI, eds. Asthma in

41 Blainey AD, Ollier S, Cundell D, Smith RE, Davies RJ. Occupational asthma in a hairdressing salon. Thora 1986;41:42-50

42 Hughes EG. Medical surveillance of platinum refiner workers. F Soc Occup Med 1980;30:27-30

43 Harrell F. The LOGIST procedure. In: SAS supplemental library users guide. Cary, NC: SAS Institute, 1983.

44 Mantel N, Haenszel W. Statistical aspects of the analysis of data from retrospective studies of disease. 7 Natl Cancer Inst 1959;22:719-48.

45 Norrish AE, Beasley R, Hodgkinson E, Pearce NE. Suspected cases of occupational asthma in New Zealand woodworking industry. NZ Med 7 1992;102:185-7. 